\title{
Valence at CoderDojos: An Exploration
}

\author{
Nigel McKelvey, Pamela Cowan \\ School of Education, Queen's University, Belfast, Northern Ireland
}

\begin{abstract}
Typically, classrooms can be an emotional place. The struggle for academic attainment often arouses some intense emotions where learners perhaps compare themselves with each other and are selflabelling as a result. Some pertinent emotions associated with achievement include an enjoyment of learning, hope for the future and pride in what is done. However, often learning is associated with negative emotion such as anger, anxiety, shame or indeed boredom. This paper looks at these issues in the context of a CoderDojo.

Due to the interactive and social nature of a CoderDojo environment, social emotions such as admiration, stress, excitement, or envy can also play a significant role in these settings. Additionally, emotions can directly influence a students' academic motivation, performance, behavior and personality development. There is little to no empirical research on student emotions in a CoderDojo context. The fluid nature of a Dojo where children learn about computer programming informally and directed by non-educationalists provides a rich topology for research and an opportunity to gain insight into how this novel environment can impact valence. This paper will utilise focus group interviews with children at four separate CoderDojo locations in one county of Ireland. The evaluation will focus on the impact of a CoderDojo on children's valence and how that might affect attitudes toward educational attainment in school. The uniqueness of a CoderDojo environment will provide cumulative knowledge that might inform educational practice in other contexts.
\end{abstract}

\section{Introduction}

A typical CoderDojo has young people between 7 and 17 years of age participating. It is not a strict rule per se with other CoderDojos extending the lower limit of 7 to younger children. The CoderDojo Foundation does not stipulate any age, only that participants should have an ability to read basic words and understand how to spell commands. The mix of ages typically enhances the experience of Ninjas (learners) as younger children learn from more experience and knowledgeable older children while the older children learn how to interact with and mentor their younger counterparts. The social aspect of the CoderDojo tends to bridge the age gap. The characteristics of a CoderDojo are such that

there is an open, friendly and positive environment created where participants are not constrained to the usual rules of a typical classroom. Talking is expected and children are actively encouraged to get up, walk about and impart their knowledge to someone else. This typically raises the emotions of children in a positive manner. There is therefore opportunity at a CoderDojo for positive valence to be associated with learning complex tasks which might ordinarily result in negative emotions of frustration, helplessness or anger in a traditional classroom setting.

It is also important to note that CoderDojos do not follow any prescribed pedagogy, therefore, any learning theories that might be evident or applied, are espoused by the mentors themselves.

\section{Review}

Information and communication technologies have become more prevalent in people's daily lives. Modelling the emotions of learners utilizing technology has become an important consideration for those involved with the delivery of and incorporation of IT in the classroom. Educators have recognised the pivotal role that emotions play in learning and the extent to which a negative impact on emotion can impede performance. More recently, [16] defined "Positive Computing" as "the study and development of information and communication technology that is consciously designed to support people's psychological flourishing in a way that honors individuals' and communities' different ideas about the good life" (p311). [2] suggests that retaining student interest and encouraging active participation are important in learning. The ability to learn effectively is diminished where a student is anxious or angry and indeed learners who find themselves in this position cannot absorb information efficiently or cope with it well [3], [14], [5]. [17] define 'social presence' as the "degree of salience of the other person in a mediated communication and the consequent salience of their interpersonal interactions." Traditional computerrelated communicative tools, such as instant messaging or e-mail, are therefore considered as having a lower social presence and ultimately social context cues when compared to face-to-face communications. It is not unusual for educators to 
spend as much time maintaining their students' emotional well-being as they do fostering their cognitive goals [9]. Many research studies have studied the impact of emotions on learning [1], [8], [11], [7]. [12] argues that emotion and cognition are inextricably linked with [4] in agreement. Emotion in learning can be aligned with constructivist theorists [13] [15]. These theories outline how to motivate and engage learners. However, they do not provide descriptions for the informal learning environment of a CoderDojo and how the various variables at play might impact upon emotion.

[18] has recently outlined how social networking and various pervasive computing technologies can be incorporated effectively in an attempt to assist in reducing feelings of social isolation and depression in elderly individuals. With social interactions being a key element of CoderDojo, the context has the potential to offer its Ninjas an environment of positivity. [19] also suggest that technology can be utilised more successfully in order to manipulate the various aspects of an experience in three interconnected ways:

a) By structuring it using a goal, rules, and a feedback system. The goal provides users with a sense of purpose by focusing attention and orienting participation in the experience. The rules (or lack thereof) can push users to view the experience in an alternative way. The feedback mechanism advises individuals how close they are to achieving the goal and provides motivation to promote tenacity.

b) By altering it to achieve mixed experiences. Technology can facilitates multisensory experiences whereby content and its interaction are offered through more than one of the senses.

c) By replacing it with a synthetic one. For example, by using Virtual Reality (VR) it is possible to mimic a physical presence in a synthetic world that might react to the user as if he/she was physically there.

A study by [20] supports the theory that user experience of technology can be a compound of emotions and perceptions of instrumental as well as non-instrumental qualities. It therefore highlights the importance that learning contexts (such as CoderDojos) must place on the selection process when choosing technologies and packages.

By using technology effectively, children can take their learning home and learn while playing games. Therefore, the influence of parents and guardians in promoting a positive learning experience with technology is important. There are many potential positive effects of technology on learning that can be conducted within the home, such as:

a) An ability to use technology for research

b) Globalization - to learn from different areas around the world c) Educational games - to make learning fun

d) Distance education - learning is not constrained by buildings

e) Web seminars - learn in a comfortable and familiar environment

Where children are encouraged in their use of technology for educational purposes at home in the same manner as in other learning contexts, the valence associated with learning and technology has the potential to increase.

For learners to feel that they own their own learning [24], it is important to include tasks which are personal. Therefore educators, in more formal contexts, might consider creating a database of student passions and hobbies so that they can connect with each other in a much more meaningful way. The CoderDojo advocates that there is no single technology [25] to be used and no single correct answer. Students can be offered an array of different ways to learn content such as video, audio, online activities, blogs, games and peer learning. Providing the learners with agency in how they approach problems is important which can also be facilitated by inviting students to add to a resource archive for all learners to access. Agency can be further fostered by inviting students to devise a subtopic within the main topic/problem area under investigation which is based on their own interests. This might be facilitated through various online tools such as Diigo or Pinterest. It is of course important to thread professionalism throughout these process by having students (and Ninjas) adhere to and understand the importance of netiquette and respect for each other. Having a personal goal can give a student focus which in itself might boost tenacity levels [26]. Perhaps these personal goals within the discipline of Computing could be aided through guidance or advice offered by experts in the field. While social media outlets such as Twitter and Facebook offer avenues for connection, perhaps LinkedIn might be considered more professional and less personal in this instance. By implementing a "knowledge sharing" platform, learners have an opportunity to see each other's work and learn new approaches implicitly. Such a platform can also enable a peer feedback process. The feedback process may be more applicable in Higher Education where students can learn to devise criteria for assessment when reviewing another's work.

According to [27], "to be tenacious means appreciating what it takes to build the mental stamina necessary to stay focused and achieve academic success. Tenacity takes gumption. Having gumption entails showing courage, determination and resilience in the midst of difficulty" (p. 5).

Recent trends in how people learn could be attributed to the dispositions that people have when entering into a learning context. [26] outline 
characteristics of a trait known as Grit where learners exude a determination in completing a task.

- $\quad$ Perseverance and Tenacity

- Deliberate Practice

- $\quad$ Ability to Delay Gratification

- $\quad$ Passion-Driven Focus

- Self-Control and Self Discipline

- $\quad$ Long Term Goal-Oriented

- $\quad$ Stick-to-it-ness Under Difficult Conditions

- Consistency of Effort

In order to facilitate and foster grit, [28] suggests that learners should be engaged with long term activities that are project based which may or may not require teams. The task at hand should require independent study specific to their own passions and interests.

[29] disputed the notion that high achievement was derived from exceptional mental ability, rather "perseverance is at least as crucial as intelligence....The most crucial inherent differences may be ones of temperament rather than of intellect as such" (p. 15). Therefore, it is significant that the CoderDojo context does not seek to gain high grades in assessments but rather to provide the learner with lifelong skills including tenacity which, arguably, is just as an important factor in success as intelligence.

[30] originally suggested that a primary developmental task of childhood was to gauge how to control the need for immediate gratification. Students nowadays live in a world where tolerating what Freud termed "a little unpleasure" is becoming increasingly difficult (p. 444). Evidence, however, is not forthcoming on this issue but it is suggested that modern technology have contributed to a world where short-term pleasures are increasingly accessible and convenient [31]. It has never been easier to indulge in diversions that feel good right away, even if they do not bring about long-term benefit. In a CoderDojo however, learners are given control of their own learning which arguably has the potential to encourage children to "stick at it" and take satisfaction from gaining success which doesn't come instantaneously.

[32] suggests that agency and tenacity can be fostered by giving learners opportunities to practice making important decisions. This can take the form of problem solving strategies, research skills as well as communication skills. However, [33] outlines that this can only occur where the educator shifts from being the 'cover the curriculum teacher' to becoming the 'guide on the side'. One avenue thought to instill traits of tenacity is that of critical thinking. A child can be encouraged to search for new ideas by using their imagination, creativity and synthesis [32]. Creative thinking affords a child the opportunity to practice skills that might facilitate exploration and experiment. The result may be that a child becomes excited about a task and due to its personal nature, is more likely to 'stick at it'.
[34] presents 'Meddler-in-the-Middle' as an "active intervenvtionist pedagogy in which teachers are mutually involved with students in assembling and/or disassembling knowledge and cultural products. Meddling is a re-positioning of teacher and student as co-directors and co-editors of their social world" (p. 288). In a CoderDojo context, 'meddlers' (mentors) may have influence due to their perceived position by the children and their professional backgrounds (as programmers or student programmers or class teachers). The energy that 'meddlers' bring to the environment does not suggest 'command and control' but rather "support and direction through structure-rich activity in which they themselves are highly involved" [34] (p. 290). This therefore suggests both the potential for a positive as well as a negative 'meddler' in an unformal context.

The unformal learning environment offered by a CoderDojo aligns itself with the theory of 'learning as inquiry' as outlined by [35]. Learning as inquiry places the question at the foreground rather than the answer and positions learning with the learner as opposed to material as part of a curriculum. It is prudent to note that answers are important, however, learning as inquiry also values the processes associated with inquiry and their impact on knowledge, skills and dispositions toward learning [35]. These impacts could have the potential to positively affect how a learner approaches learning in all walks of life.

\section{Overview and Methodology}

This study explored the experiences of children (aged 10-13 years old) participating in CoderDojos in one county of Ireland. The research incorporated qualitative (observations and focus groups) methods. Four CoderDojo Locations (A, B, C and D) were identified. These four locations had an existing Dojo (running for more than 12 weeks). They were selected due to their profile diversity and geographic location. The children here were observed, completed a survey and participated in focus group interviews.

CoderDojo A: A CoderDojo operating after school hours within a secondary school where the mentor is not a teacher.

CoderDojo B: A CoderDojo operating at a Family Resource Centre where the mentors are computing students from Higher Education as well as computing professionals.

CoderDojo C: A CoderDojo operating during class time in a primary school where the mentor is their usual class teacher.

CoderDojo D: A CoderDojo operating after school hours within a secondary school where the mentors are working computing professionals (programmers). 
The advantages of focus groups for this study, are such that they included the ability to capture data in a social environment, the interviews were flexible, had high face validity, ensured speedy results, were relatively low in cost and had the potential to highlight issues the researcher had not considered. However, focus groups can often offer less control than individual interviews, the data can be difficult to analyse and the researcher must be relatively skilled. If more than one group is used on the same topic, then the difference between groups can become troublesome. It is also often the case that groups are difficult to assemble so as to suit everybody and the discussion must be conducted in a conducive environment. The qualitative aspect of this study permitted a greater depth of understanding of CoderDojos. There was flexibility and opportunity to modify the research at any time. Arguably, qualitative research, in this instance, has more validity than surveys or experiments due to the social aspect that exists within CoderDojos.

Through a methodology involving focus group interviews and observations, the researcher's role might be to describe a phenomenon from a participant's perspective [22]. This results is an emic interpretation of those experiences. Qualitative research assumes the right to anonymity and therefore ethics played an essential part of this study as the researcher is a lecturer in Computer Science and therefore might have been considered part of the process with the ability to affect the data emerging from observations [22]. Having ethical clearance to conduct the study was important but is often considered extrinsic to the research as the approval tends to emerge from external committees or formal codes of conduct [21]. To alleviate any ethical concerns, the participants were not known to the researcher.

For the purposes of this paper, one category from the thematic analysis of the focus groups is presented; namely that of valence at CoderDojo.

\begin{tabular}{|l|l|l|}
\begin{tabular}{l|l|} 
Table 1 Focus Group Participants \\
Location
\end{tabular} & Male $\boldsymbol{n}$ & Female $\boldsymbol{n}$ \\
\hline$A$ & 3 & 3 \\
\hline$B$ & 4 & 2 \\
\hline C & 3 & 3 \\
\hline$D$ & 5 & 1 \\
\hline
\end{tabular}

The table above outlines how many children were interviewed at each location.

The primary goal of the interviews was to make known beliefs held by the interviewee by revealing the conceptual structures that resided inside them [6]. Interviews were deemed more advantageous in data collection than questionnaires as the researcher was able to clarify any misunderstandings of the respondents. Furthermore, during the interview the researcher explored concepts more deeply and was able to stimulate fuller answers. The present study used four focus group interviews (4-6 participants in each) which resulted in richer responses and facilitated a much wider range of viewpoints due to data being prompted by others' opinions [10]. The researcher conducted the interviews with a range of set questions which were used as a guide. The questions became organic as the interviews progressed allowing for a more natural dialog to occur. The group interviews took place at each location during a time that suited all involved. Full informed consent was gained from parents, mentors and assent gained from the children themselves. Each group interview was audio-recorded and transcribed. All names have been anonymized by using pseudo names.

\section{Analysis}

Billy (CoderDojo B) relayed the pride he felt about his own work and Mary relayed her interest in personal projects. The children at location D also enjoyed receiving feedback with Susan using this feedback as an opportunity to teach her sister.

\section{CoderDojo B}

Researcher: And would you show family or friends what you do, if friends come over to visit or play? Do you show them?

Billy: Yes I would. I'd be very proud of my work.

\section{CoderDojo B}

Researcher: Do you work on CoderDojo at home?

Mary: It depends how interested in the project I am. Like I was doing one before Valentine's Day, I didn't get to finish it cos I got homework and all that.

Mary: Sometimes I, but I was really interested in it at the start, and that's all I was doing in the evenings, but it depends how interested I am in the project.

\section{CoderDojo D}

Researcher: Ok. Ok and do you like to get that feedback from other people?

Jimmy: Yeah.

Tommy: Yeah. 


\begin{abstract}
Researcher: Yeah.
Susan: Yes I definitely explain to my family what I'm doing in CoderDojo. Show them what I've been working on at home and I suppose because I'm home schooled as well, I can show my mom and my dad and my twin sister all the different things I've been doing. So that's great, I'm almost kind of teaching my twin sister, then how it's all done. She doesn't have as great an interest in computers as me but I think she still finds it interesting.
\end{abstract}

The positive reinforcement within the home environment reinforces that sense of pride which children often need and alludes to the fact that, in this example, coding is valued in the home. It is the author's opinion that pride has encouraged the children to go off and learn more. They are taking control and deciding what to learn and how they are going to learn it. The positive valence associated with showing personal projects to family and friends is perhaps instilling a desire to do more, particularly when the work is of their own choosing.

Some of the children at CoderDojo C showed their work at home but it appeared to be more out of boredom and alluded to the fact that their parents either weren't particularly interested or did not understand it. It is arguable that perhaps this negative valence is impacting their agency to the point where they are relying upon their teacher to help guide them as opposed to taking ownership of their own learning.

\section{CoderDojo C}

Researcher: And do you show, em any of your family members or do you show other friends who maybe don't have Coderdojo?

Eve: Em, normally if, normally, the odd time if I like have nothing really to do I normally go on my account normally start like making something on Scratch and then I normally like get my Mum and Dad and show them what I've done and like how to work, how I worked it and all.

Peter: I normally show my Mum and Dad kinda what I do at school and I do like a tiny bit at home, and I would show like what we did in school and what I did just there now. Well it kinda depends on your personality, if you have patience or if you don't have patience, like if ya didn't have the patience you would probably try it at home. But if ya did have patience you would probably wait until your teacher, nuh, until you go back to school, because sometimes your teacher knows like more about computers than your Mum and Dad.

The opportunity to engage in limitless problem solving where the learner exhibits determination (tenacity) and recognises that there are more than one way to achieve a result is evidenced by John when he says:

\section{CoderDojo B}

John: Well coding, ya see, there's loads of ways of doing it. If ya wanted to write a word you could write a small code or a big code, and you could do it many ways, only with school subjects, there's just limits whatever way whatever direction ya go.

John's response also suggests that his options to learn are limited in a traditional school environment. The notion of a school applying "limits" and being restrictive is a cause for concern for educationalists. Offering learners opportunities to engage with a task in multiple ways is certainly a trait of CoderDojo that could be implemented in a school setting. This of course assumes that there is time and scope within the curriculum to facilitate this.

John's comments are supported by children at CoderDojo A where they also suggested that there was less opportunity for agency in learning at traditional school.

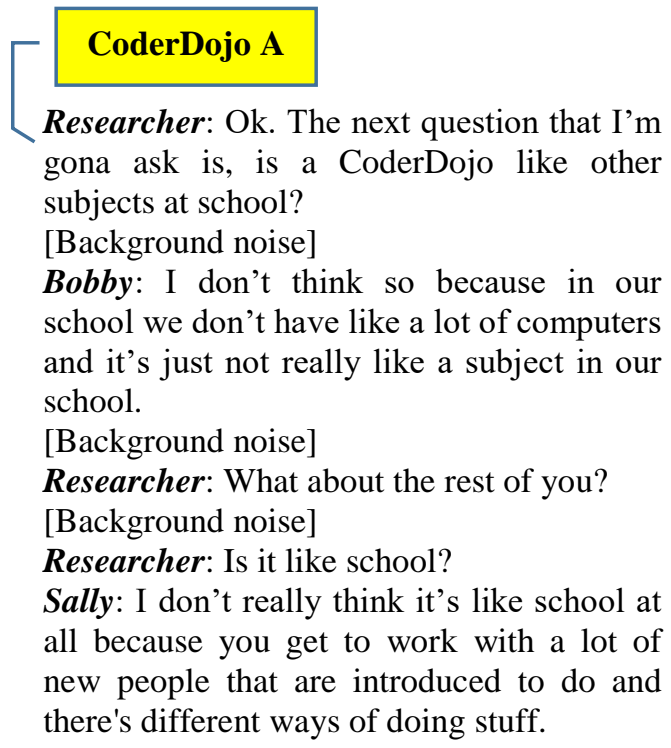

Sally mentioned being introduced to new people at a CoderDojo. The social aspect of a Dojo is important where children of different ages are learning together. 
The focus group interviews revealed what fun meant to the children and how it influenced and affected their approach.

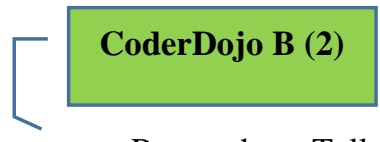

Researcher: Tell me what you think of a CoderDojo?

Billy: Um, Well I think its very fun and like your imagination... there's no limit to it. Like you can, whatever you can think of you can do it.

Billy at CoderDojo (B2) appeared to cite a Dojo as a context that provided him with a world of possibilities. He referred to the fun aspect of using his imagination and that in turn, anything was possible.

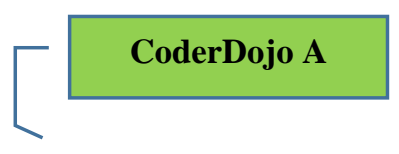

Researcher: Tell me what you think of CoderDojos?

Paul: I think it is great for the mind and it gets it racin and if you ever wanted a job with computers as you grow up, this is probably the thing for you.

In a similar way to Billy at $\mathrm{B}(2)$, Paul alludes to his enjoyment of the Dojo referring to his mind "racin". The positivity he associates with the Dojo is perhaps linked to the stimuli presented to him. Again, the positive language suggests that there were no comprehension challenges for the child but rather an enjoyment of the challenge. There is also aspiration in his dialogue and an appreciation for the role of programming as a career.

A CoderDojo is an opportunity for children to learn from and with peers. However, attracting females to CoderDojos is a challenge. During the focus groups, the children spoke about gender.

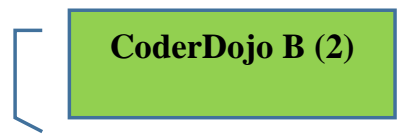

Researcher: What would we do to make girls more interested in coding?

Billy: Umm, maybe put more girly concepts into it.

Researcher: What's a girly concept?

Billy: Well...

John: You can make anything. It's just what you think of putting in it. Aw I just think, they just wouldn wana do it anyways. No matter what it's like.
Billy: They're just distracted by other things.

Bob: Yeah. Even someone made a project about pink fluffy unicorns dancing on rainbows.

Billy: Well like, girls don't just like pink things, and flowers and love hearts, that's what we think. That's the stereotype.

The boys at location $\mathrm{B}(2)$ almost demonstrated apathy towards encouraging females to attend a Dojo. They felt that there was nothing that could be done. However, Bob's comment about "pink fluffy unicorns dancing on rainbows" was quickly refuted by Billy who spoke of stereotypes. The boys' idea of what might be fun for the girls appeared to be an allusive goal. It does however raise concerns as to how Dojo organisers might make the environment and tasks either more gender neutral or more gender specific in order to attract more females. Arguably, the misconception, as outlined above, that a Dojo is about gaming, is something that the CoderDojo Foundation might consider moving forward. [36], [37], [38] have outlined that often public game spaces are dominated by males and as a result serve to exclude female gamers. This may exasperate the perception that interacting with digital games is a male preserve. The research does suggest that games development could be a possible reason why the number of females undertaking degrees in computing have fallen in recent years.

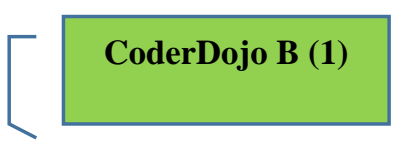

Researcher: Why do you think more girls don't do CoderDojo? Yeah Luke?

Luke: Cos they think they'll be nerds.

Researcher: Do you agree girls?

Mary: No.

Ann: No.

[Laughing]

Researcher: Tell me why you don't agree then.

Ann: Cos all girls are different.

The girls in this instance disagreed that females are afraid of being labelled a nerd. However, they did not provide any reasons as such as to why girls don't attend in greater numbers. The discussion with these children did reveal additional related data pertaining to what might be perceived as fun: 


\section{CoderDojo B (1)}

Researcher: Ok. Thank you guys. So the very first thing I want to ask you today is, can you tell me what you think of CoderDojos?

Ann: Fun.

Luke: It like it would inspire you to make games when you grow up.

Researcher: Ok, what about you girls, any opinion? What do you think CoderDojo is, or what do you think about CoderDojo?

Mary: Imaginative.

Researcher: Imaginative, Yeah good word. Ann: Um, you can be creative.

Researcher: And um, why do you go to a CoderDojo?

Luke: Aaaaah, well whenever aaaah, well whenever I'm older, um I can teach, um if I have kids um and I get a laptop, aaah I can get, I can teach my, I can, I can teach my kids games.

Luke: Also, in school um, you get judged for your um, am, for like say if like um, you make a very violent game.

Ann: Using different colours.

Ann: I like colourful projects.

In this dialog, the children were asked to give their thoughts about a CoderDojo. The boys tended to use words such as "inspire", "make games", "teach", "laptop" and "violent game". To them, the aspect of fun appeared to be something technical, games-based and with a view to gaining future proficient skills. It is arguable that this dialog reveals an attitude where the boys were focused, studious and took the CoderDojo seriously. While the girls weren't any less serious in their attitude, the words they used about their Dojo were, "fun", "imaginative", "creative", colours" and "colourful projects". The difference in adjectives is quite strong between the genders. The girls appeared to be using the space to engage in creative activities that were personal to them. The words they used didn't appear to allude to any aspiration to become a programmer but rather an opportunity to use their imagination in an innovative way. The dialog possibly reveals a strong relationship between the children, the tools they are using and the outcome they are hoping to achieve. The relationship is fostered and aided by the mentors. Combined, it is possible to suggest that these children are working within their Zone of Proximal Development (ZPD) with agency as they are being scaffold to attain their own personal goals by learning in a way that suits their own individual needs.

There is good opportunity for the children to learn how to interact with others in a more productive manner and to learn empathy for others who might be encountering difficulty. These options are often not available in a school setting where, traditionally, a class is comprised of children of a similar age. It is therefore arguable that a CoderDojo is providing its Ninjas with agency in their approach to learning; a potential lifelong skill.

\section{Conclusions}

Arguably the more successful CoderDojos studied, utilised non-educationalists as mentors. In a school setting, it is possible that the children perceive the usual teacher/student hierarchy and therefore treat the CoderDojo as a normal school subject. This may be somewhat circumvented in school settings where the teacher does not deliver the Dojo but rather a non-educationalist (mentor(s)) act as guides and advisors. The perceived hierarchy does not appear to be prevalent in CoderDojo locations that are out-of-school hours and/or school context. Where computing professionals/students are acting as mentors with no prescribed theories of learning and no pressure to attain grades, the children appeared to be more empowered and exhibited a greater passion for the discipline.

Therefore, schools might consider the adoption of policies that might include more non-educationalists in content delivery and assessment design. While the application may be obvious with the Computing discipline, it might appear more ambitious in other disciplines such as Law, Engineering, Maths, Business, Science or Humanities, however, bringing professionals into the classroom (primary, postprimary or Higher Education) has the potential to reinforce theory taught, the potential to breathe life into stagnant curriculum and to provide learners with 'real-life' examples and context. It may also provide learners with opportunities to engage with and question professionals working within the field. In keeping with [23], it is important that learners do not exit a module or course of study with a false sense of a particular discipline. To do so has the potential to stifle creativity and constrain knowledge. It is also important that learners are afforded opportunity to explore alternatives to the textbook and to question the prescribed narrative of a curriculum. In doing so, the learner may gain additional thinking skills and navigate the ZPD more confidently. Where a noneducationalist can assist in the design of an assessment, it has the potential to add a new layer of authenticity to the task and ultimately increasing the validity of grades. The successes evidenced by the CoderDojos researched as part of this study, serve to 
indicate the potential positive impact noneducationalists can have on learning.

As an educator, one would wish to encourage children to devise their own ideas about learning. As a result, children can learn in a manner that suits their own individual needs. CoderDojos facilitate this through its heuristic approach and the nonhierarchical approach adopted by mentors.

The research presented in this paper demonstrates the potential of a CoderDojo to enhance emotional intelligence. The tools associated with a Dojo such as Scratch (used for concept building and developing rudimentary code) and Sushi cards (instructions) can support the Ninjas' emotional connection to content or other people. Arguably, the positive valence aids a child in learning. The flexibility of tools and technologies used at a CoderDojo enables the children to learn based on how they feel most comfortable or confident which is also associated with agency. The fluid nature of a Dojo can provide private spaces for the children to explore problematic issues and allow a studious approach to problem solving when or where necessary. It is the author's opinion that empathy can be enhanced through emotional learning via the use of technology. For example, at a CoderDojo, Ninjas may develop empathy by viewing each other's personal projects or indeed by watching and helping others who are experiencing distress or problems in resolving a complex issue.

Additional research may also yield answers pertaining to the levels of resilience associated with positive educational environments and the impact of perceived mentor support in contributing to learner success. A future study might also determine whether the positive environment of a CoderDojo can impact upon other areas of a child's life.

\section{References}

[1] Baddeley, A. (1986). Working Memory. Oxford Psychology Series No. 11 Oxford, UK: Clarendon Press.

[2] Bransford, J., Brown, A. and Cocking, R. (2000). How people learn: brain, mind, experience and school. Committee on Developments in the Science of Learning, NRC Commission on Behavioral and Social Sciences and Education. Washington, DC: National Academy Press.

[3] Burleson, W. and Picard, R. (2004). Affective agents: sustaining motivation to learn through failure and a state of stuck, social and emotional intelligence in learning environments workshop. 7th International Conference on Intelligent Tutoring Systems.

[4] Cytowic, R. (1989). Synesthesia: A Union of the Senses. New York: Springer Verlag.

[5] Goleman, D. (1995). Emotional Intelligence. New York: Bantam Books.
[6] Halldén, O., Haglund, L. and Strömdahl, H. (2007). Conceptions and Contexts: On the Interpretation of Interview and Observational Data. Educational Psychologist. 42 (1). p. 25-40.

[7] Kort, B., Reilly, R. and Picard, R. (2001). External representation of learning process and domain knowledge: affective state as a determinate of its structure and function. Workshop on Artificial Intelligence in Education (AI-ED 2001).

[8] Lepper, M. and Chabay, R. (1988). Socialising the intelligent tutor: bringing empathy to computer tutors. Learning Issues for Intelligent Tutoring Systems. p. 242257.

[9] Lepper, M. and Hodell, M. (1989). Intrinsic motivation in the classroom. In: C. Ames and R. Ames Research on Motivation in Education. New York: Academic Press.Vol. 3. p. $73-105$.

[10] Lewis, A. (1992). Group child interviews as a research tool. British Educational Research Journal. 18. p. 413-421.

[11] Mandler, G. (1984). Mind and Body: Psychology of Emotion and Stress. New York, NY: WW Norton \& Co.

[12] Norman, D. (1981). Twelve issues for cognitive science. In: Hillsdale, N. Perspectives on Cognitive Science. p. 265-295.

[13] Piaget, J. and Inhelder, B. (1969). The Psychology of the Child. New York: Basic Books.

[14] Picard, R., Papert, S., Bender,W., Blumberg, B., Breazeal, C., Cavallo, D., Machover, T., Resnick, M., Roy, D. and Strohecker, C. (2004). Affective learning - a manifesto. BT Technical Journal. 2 (4). p. 253-269.

[15] Vygotsky, L. (1978). Mind in Society: The Development of Higher Psychological Process. Cambridge, MA: Harvard University.

[16] Sander, T. (2011). Positive Computing. Positive Psychology as Social Change. p309-326.

[17] Short, J., Williams, E., and Christie, B. (1976). The social psychology of telecommunications. London: John Wiley \& Sons.

[18] Morris, M. (2005). Social networks as health feedback displays. IEEE Internet Computing. 9(5). p29-37.

[19] Riva, G., Baños, R., Botella, C., Wiederhold, B. and Gaggioli, A. (2011). Positive Technology: Using Interactive Technologies to Promote Positive Functioning. Cyberpsychology, Behavior, and Social Networking. 15(2). p69-77.

[20] Thuring, M. and Mahlke, S. (2007). Usability, aesthetics and emotions in human-technology interaction. International Journal of Psychology. 42(4). p253-264.

[21] Guba E. and Lincoln, Y. (1994). Competing Paradigms in Qualitative Research. In: Denzin, N. and 
Lincoln, Y. Handbook of Qualitative Research. London: Sage. p105-117.

[22] Orb, A., Eisenhauer, L. and Wynaden, D. (2000). Ethics in Qualitative Research. Journal of Nursing Scholarship. 33 (1). p93-96.

[23] Nokes, J. (2011). Recognizing and Addressing the Barriers to Adolescents' "Reading Like Historians". The History Teacher. 44(3). p379-404.

[24] Glasser, W. (1998). Choice Theory. New York: Harper Collins.

[25] Jost, M. (1999). Theory into practice: social constructivism and technology in instructional technology and teacher education. Retrospective Theses and Dissertations.

[26] Duckworth, A. and Quinn, P. (2009). Development and validation of the Short Grit Scale (GRIT-S). Journal of Personality Assessment. 91(2). p166-174

[27] Pearse, M. and Dunwoody, M. (2013). Learning That Never Ends: Qualities of a Lifelong Learner. United Kingdom: Rowman \& Littlefield Education.

[28] Gerstein, J. (2013). Grit: The Other 21st Century Skills. Available: https://usergeneratededucation.wordpress.com/2013/ 06/01/grit-the-other-21st-century-skills/. Last accessed 27th August 2015.

[29] Howe, M. (1999). Genius explained. New York: Cambridge University Press.

[30] Freud, S. (1920). Introductory lectures on psychoanalysis. New York, NY: Norton.

[31] Moffitt, T., Poulton, R. and Caspi, A. (2013). Lifelong Impact of Early Self-Control. American Scientist. 101. p352-359.

[32] Gregory, G. and Kaufeldt, M. (2015). The Motivated Brain: Improving Student Attention, Engagement and Perseverance. USA: ASCD.

[33] Hattie, J. (2009). Visible learning: A synthesis of over 800 meta-analyses relating to achievement. London, UK: Routledge.

[34] McWilliam, E. (2009). Teaching for creativity : from sage to guide to meddler. Asia Pacific Journal of Education. 29(3). p281-293.

[35] Goldman, S., Radinsky, J., Tozer, S. and Wink, D. (2010). Learning as Inquiry. In: Aukrust, V. G Learning and Cognition in Education. Oxford: Elsevier Limited. p154-159.
[36] Haddon, L. (1993). Interactive Games. In: Hayward, P. and Wollen, T. Future Visions: new technologies of the screen. BFI, London.

[37] Bryce, J. and Rutter, J. (2002). Killing like a Girl: Gendered Gaming and Girl Gamers' Visibility. In: Mayra, F. Computer Games and Digital Cultures. Tampere University Press.

[38] Wright, T. and Briedenbach, P. (2002). Virtual Violence, Social Meaning and Gender: Competition and Cooperation between FPS Game Players. Challenge of Computer Games. 